\title{
Rehabilitation of spinal cord injury in the national rehabilitation center for the disabled of Japan: profile of a spinal service
}

\author{
T Suyama, R Nihei, T Kimura, H Yano, Y Tobimatsu, Y Hatsuyama, R Nakamura and M Mizukami \\ Department of Orthopedics, National Rehabilitation Center for the Disabled Hospital, Saitama Prefecture, Japan
}

\begin{abstract}
The National Rehabilitation Center for the Disabled (hereunder abbreviated NRC) in Japan was established in 1979. It consists of four divisions: the hospital, the rehabilitation training center, the research institute, and the information service section. The spinal unit has been functioning and cooperating corelatively with all of these divisions. There were 1047 patients with a spinal cord injury treated in the 15 years from September, 1980 to August, 1994; consisting of 924 males $(88.3 \%)$, and 123 females $(11.7 \%)$. The breakdown of causes of injury were traffic accidents $44.9 \%$, having a fall $14.7 \%$, sports accidents $6.7 \%$, and other causes of spinal paralysis $10.5 \%$. The sites of the spinal cord lesions were cervical $372(35.5 \%)$, thoracic $547(52.5 \%)$, and lumbar spinal cord 128 patients $(12.3 \%)$. The incidence of complete paralysis in those with a cervical spinal cord injury (SCI) was 68.8\%, and for thoracic and lumbar SCI $79 \%$ each. The time for completion of activities of daily living (ADL) was $12.0 \pm 1.54$ months in those with tetraplegia, and $5.6 \pm 1.71$ months for those with paraplegia. The rate of employment for reentry into society was $59 \%$ in those with a cervical spinal cord injury, and $74 \%$ each in those with a thoracic or lumbar spinal cord injury.
\end{abstract}

Keywords: spinal cord injury; National Rehabilitation Center for the Disabled; Japan; profile of a Spinal Service

\section{Introduction}

SCI patients in Japan are admitted to emergency hospitals, including emergency and lifesaving centers in university hospitals. They are then transferred to a hospital where the SCI is treated comprehensively. In the NRC, the spinal cord injured person in the subacute to chronic stage is treated including intensive rehabilitation.

\section{History}

The NRC was established by the Ministry of Health and Welfare in 1979 to contribute to the promotion of welfare for the physically disabled through comprehensive rehabilitation services and techniques.

In the NRC, people with physical handicaps, or visual impairment, or hearing impairment are also treated, which is an uncommon arrangement in the world. The rehabilitation services for the spinal cord injured are provided in the section for those who are physically handicapped.

\section{Organization}

In the organization of the $\mathrm{NRC}$, the following four activities are conducted (Figure 1).

Correspondence: T Suyama
Comprehensive rehabilitation services

After completion of a study at an evaluation conference by a rehabilitation team which consists of professional staff, such as a doctor, a nurse, a physiotherapist (PT), an occupational therapist (OT), a remedial gymnast, a speech therapist, a prosthetist, an orthotist, a psychologist, a vocational evaluator, and a social worker, the individual rehabilitation program is prepared and training is given with the aim of the patient being reentered into society.

Research and development of rehabilitation techniques Clinical survey and rehabilitation research techniques in various fields are conducted; prosthetics and orthotics are developed and manufactured, and repair services are provided.

\section{Training of professional staff}

The Diploma Course for rehabilitation workers such as speech therapists, sign interpreters, prosthetists, orthotists, and rehabilitation sports specialists, and Short-term Training Courses are established; for doctors, PTs OTs, psychologists, vocational evaluators, social workers, and the other specialists who are engaged in relevant rehabilitation activities across the nation. 


\section{ORGANIZATION}

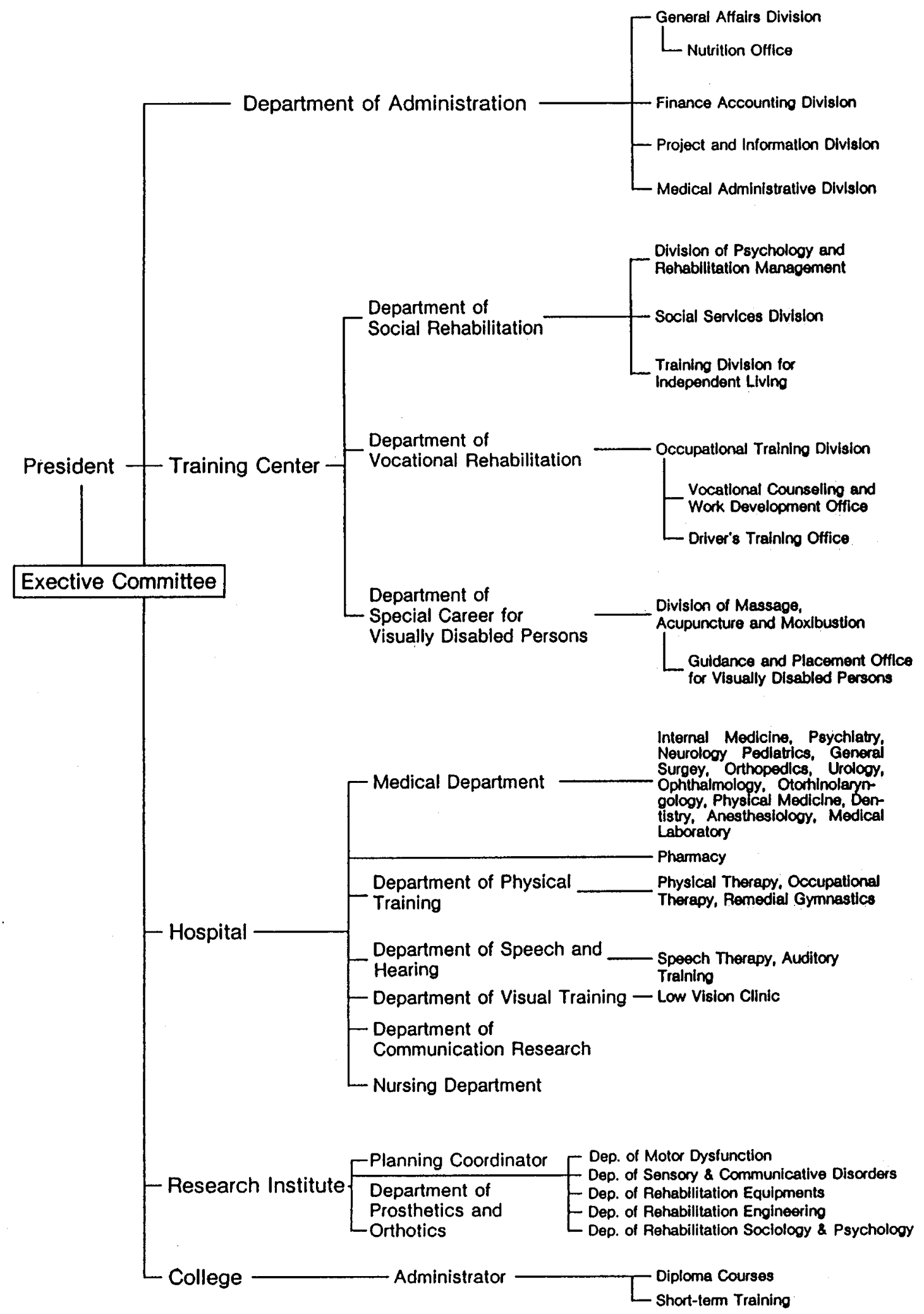

Figure 1 
Information services

Information and materials on rehabilitation are collected and disseminated nationally and internationally.

\section{Spinal unit}

In the hospital in the $\mathrm{NRC}$, orthopedists, doctors specializing in rehabilitation, and urologists are in charge of activities in the spinal unit and physicians are in charge of the comprehensive treatment of respiratory, circulatory, and digestive conditions.

\section{Department of physical training}

In the Department of Physical Training, the following four activities are conducted:

\section{Physical therapy}

Physical function is strengthened by therapeutic exercise, hydrotherapy, electrotherapy, etc.

\section{Occupational therapy}

Functional and preventive training for reentry into society, and the counseling services for housing are conducted for the independence in ADL and improvement in the quality of life.

\section{Remedial gymnastics}

Remedial gymnastics such as gateball, archery, swimming and basketball are held for the recovery of physical function and the cultivation of cooperative spirit and the sense of responsibility.

\section{Driving lessons}

\section{Vocational rehabilitation}

After the completion of various rehabilitation training in the hospital, patients who wish to have vocational training apply for vocational rehabilitation in the Vocational Training Center and receive supportive training there.

\section{Statistics concerning the rehabilitation of the spinal cord injured}

\section{Number of patients}

There were 1047 patients who were in the hospital from September, 1980 to August, 1994. Sex; There were 924 males $(88.3 \%), 123$ females $(11.7 \%)$ and the male-to-female ratio was about $7: 5: 1$.

Occurrence of injury; The mean age was 33 $(\mathrm{SD}= \pm 13.3)$ and the incidence of patients in each age group were teens $10 \%, 20 \mathrm{~s} 42 \%, 30 \mathrm{~s} 20 \%$, 40s $13 \%, 50 \mathrm{~s} 7 \%, 60 \mathrm{~s} 4 \%$, and $70 \mathrm{~s} 2 \%$ as shown in Table 1 .
Causes of Injury; The etiology of the SCI was as follows. Motorbike accidents $28 \%$, car accidents $16.9 \%$, and the combined rate of those two traffic accidents was $44.9 \%$ : having a fall $14.7 \%$, sports accidents $6.7 \%$, falling $2.2 \%$, tumbling in walking $1.4 \%$, and cycling accidents $1.3 \%$ as shown in Table 2 . Myelitis, arterial and venous deformation, and spinal cord tumors caused SCI in $10.5 \%$ of the patients (Table 2).

Level of the spinal cord lesion; Cervical spinal cord, $372(35.5 \%)$, thoracic spinal cord $547(52.2 \%)$, lumbar spinal cord, $128(12.3 \%)$ (Table 3). Neurological levels; Complete cervical SCI, 68.8\%: thoracic and lumbar SCI, $80 \%$ each: incomplete cervical SCI, $31.2 \%$ : thoracic and lumbar SCI $20 \%$ each.

\section{Rehabilitation}

Independence in ADL: For those with tetraplegia and paraplegia with no associated injury or complications, and who started rehabilitation in the NRC less than 2 months after the injury, the necessary time for independence in ADL was $12.0 \pm 1.54$ months, and $5.6 \pm 1.71$ months respectively. For those who did not start early rehabilitation because of associated injuries and complications, the periods were $19.3 \pm 6.05$ months, and $12.3 \pm 4.35$ months respectively (Table 4 ).

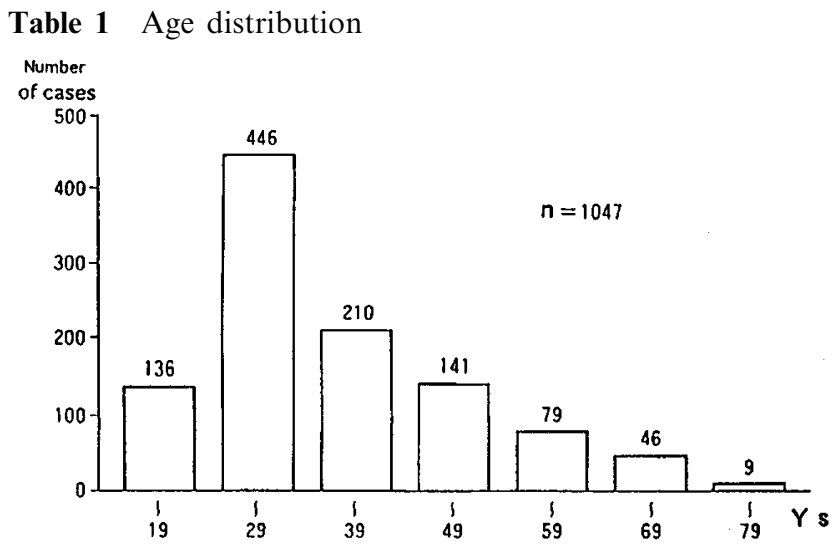

Table 2 Cause of accident

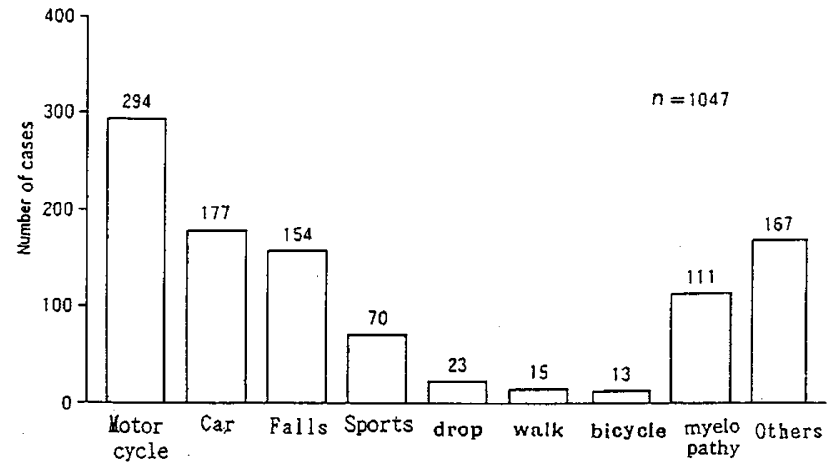


Table 3 Level of spinal cord injury

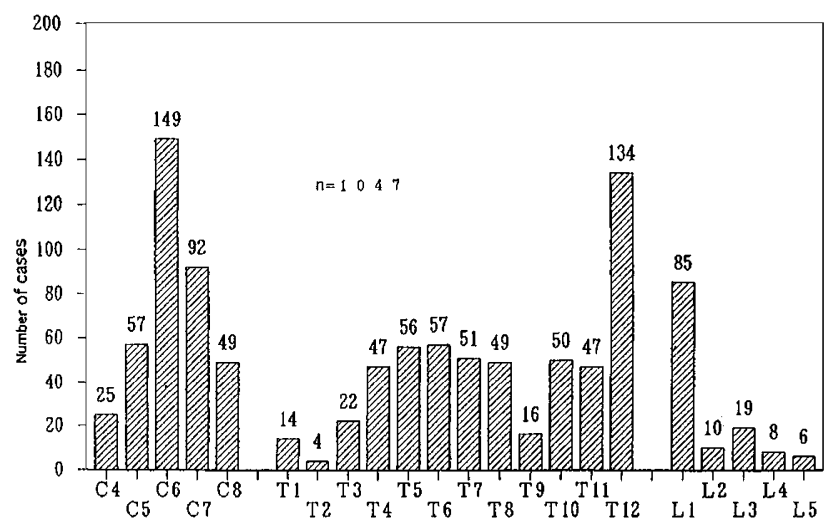

Table 4 Total independence of ADL (Complete paralysis)

\begin{tabular}{lcc}
\hline & $\begin{array}{c}\text { Complication }(-) \\
\text { Early }\end{array}$ & $\begin{array}{c}\text { Complication }(+) \\
\text { Early } \\
\text { rehabilitation }(+)\end{array}$ \\
& rehabilitation $(-)$ \\
\hline Tetraplegia & $12.0 \pm 1.54$ Months & $19.3 \pm 6.05$ Months \\
Paraplegia & $5.6 \pm 1.71$ Months & $12.3 \pm 4.35$ Months \\
\hline
\end{tabular}

mean $\pm \mathrm{SD}$

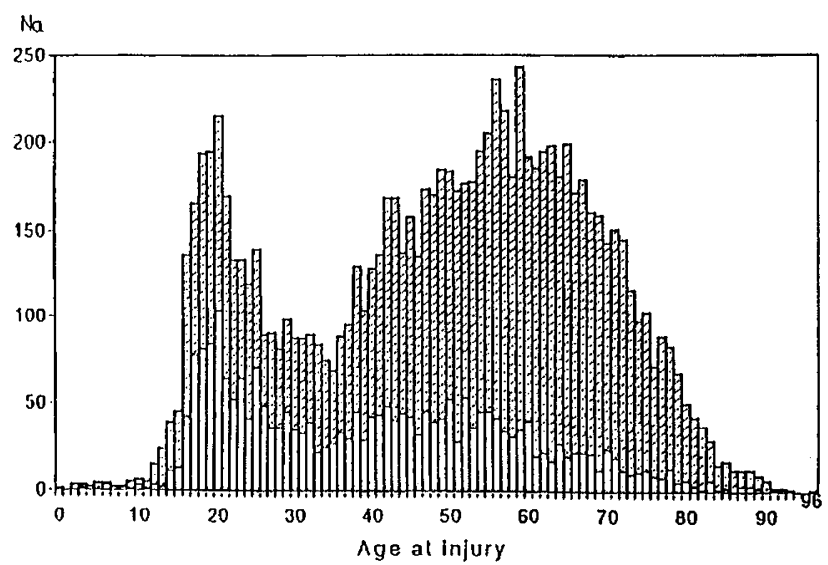

Figure 2 Age distribution at the time of injury

Achievement of ADL: The accomplishment rate of independence in ADL for each spinal cord lesion was $100 \%$ in Zancolli 3-A or Below, $85 \%$ in 2-B-II, and $53 \%$ in $2-\mathrm{B}-\mathrm{I}$; patients in $1-\mathrm{A}$ and $1-\mathrm{B}$ required partial assistance.

Delay of training for ADL, and delaying factors; These were: (1) Pressure ulcers; When patients were admitted to hospital, the incidence of pressure ulcers was $50.8 \% ; 44 \%$ sacral, $28 \%$ over the greater trochanter of the femur, and the ischium $28 \%$. Hospital costs for 10 patients, each sampled at random were as follows: Without pressure ulcers: Y5 061 553. Large and deep pressure ulcers with infection: Y14 $767276(P<0.001)$.

Fixation and rigidity of the spine. Long metallic instrumentation of the spine impeded ADL. The independence rate of ADL in the following spinal cord lesion in operated and non-operated groups were expressed as a score and assessed with the modified Barthel Index: ${ }^{1}$ At $\mathrm{T}_{1}$ to $\mathrm{T}_{7}$, patients in the operated group had higher scores until 3.4 months after the operation, but after this, it was reversed; patients in the non-operated group became independent 1.4 months earlier than those in the operated group.

Spasm: Antispasmodic drugs were given, also blocking of nerves, FES, and facilitation, when spasms hindered training and ADL, tendon elongation and tenotomy was used for $5 \%$ of the patients, with good results.

Ectopic Bone Formation: The incidence was 5.6\%: at the hip joint $73 \%$, the knee joint $17 \%$, and the elbow joint $8 \%$.

Pain: Among 84 patients with paraplegia, pain was prominent in $43(51.2 \%)$. In those with spinal internal fixation, pain was felt in the surrounding area of the metallic spinal instrumentation and after their removal of this, the pain disappeared in $82.1 \%$. Pain in the paralyzed regions in the non-operated group disappeared in only $26 \%$ with drugs, thermotherapy, and exercise therapy.

Psychological changes: Soon after injury, patients became psychologically unstable, with limitation of physical activities, and poor neurological recovery. The incidence of patients who had difficulty in accepting their injury and hindering their training was $6.7 \%$. Among $71.1 \%$ of those with paraplegia, dysthymia, anxiety, decline of volition, and depression were found in $71.1 \%$ and psychotherapy was required.

Reentry into Society. The number of spinal cord injured entrants for the rehabilitative training center between 1979 and 1997 was 563, with a mean age of 24.5. The spinal cord lesion was cervical in 158 patients $(28 \%)$; thoracic in $337(59.8 \%)$; and lumbar in $68(12.2 \%)$. The employment rates for those with a cervical spinal cord lesion was $59 \%$; and for thoracic and lumbar spinal cord lesion $74 \%$ each.

\section{Topic for discussion}

The annual incidence of traumatic SCI between 1990 and 1992 was 40.2 in $1000000 .^{2}$ According to the survey held in Japan in these years, people between 20 and 59 years of age, were most likely to develop a traumatic SCI: ${ }^{3}$ this is quite different from reports from other countries. ${ }^{4,5}$ Elderly people with spinal changes from aging may have a cervical SCI, especially with incomplete paralysis, from a fall or a crash (Figure 2). ${ }^{6}$

Among the causes of injury, traffic accidents and falls were the most frequent; similar to reports by Murray $^{7}$ in 1984 and Chen ${ }^{8}$ in 1995. It is characteristic that there are no gunshot injuries in Japan; but diving 
accidents into a pool are common and preventive measures are urgently required.

Delaying factors for rehabilitation are pressure ulcers, a rigid spine, ectopic bone formation, pain, autonomic dysreflexia, and psychological changes. 9,10 It is important that employers are urgently required to accept those who have had a spinal cord injury as an employee, and provide environments accessible for them.

\section{References}

1 Mahoney FI. Functional evaluation: The Barthel index, Maryland State Medical J., Annual Meeting, April 1965, pp. 603-605.

2 Shingu H. Epidemiology of the spinal cord injury in Japan from 1990 to 1992. The Journal of the Japan Society of Paraplegia 1995; 8: 26
3 Hatsuyama Y, Nihei R. Comprehensive rehabilitation services for spinal cord injury. 1996, pp. 13-23.

4 Campos da Paz A et al. Traumatic injury to the spinal cord. Prevalence in Brazilian hospitals. Paraplegia 1992; 30: 636-640.

5 Minarie $\mathrm{P}$ et al. Epidemiology of the spinal cord injury in the Rhone-Alpes Region, France, 1970-1975. Paraplegia 1978; 16: $76-78$.

6 Fife $\mathrm{D}$ et al. Anatomic location of spinal cord injury. Relationship to the cause of injury. Spine 1986; 11: $2-5$.

7 Murray PK et al. Epidemiology of nontraumatic and traumatic spinal cord injury. Arch Phys Med Rehabil 1984; 165: 634.

8 Chen CF. Spinal cord injuries in Taipei, Taiwan, 1978-1981. Paraplegia 1985; 23: $362-370$

9 Angelo R, Canedo Ph.D. The Psychological impact of spinal cord injury. Medical Complications of Quadriplegia 1986, pp. $11-24$.

10 Guttmann L. Spinal cord injuries, 2nd ed., Blackwell Scient. Pub., Oxford, 1976. 